\title{
Nature-Based Therapy for People Suffering from Post-Concussion Syndrome-A Pilot Study
}

\author{
Sus Sola Corazon ${ }^{1}$ (D), Lisbeth Jul Olsen², Anne-Marie Olsen ${ }^{3}$, Ulrik Sidenius ${ }^{1}$ \\ ${ }^{1}$ Department of Geosciences and Natural Resource Management, University of Copenhagen, Frederiksberg, \\ Denmark \\ ${ }^{2}$ Municipality of Copenhagen, Health Care Center, Noerrebro, Denmark \\ ${ }^{3}$ Frederiksberg Health Center, Frederiksberg, Denmark \\ Email: suoe@ign.ku.dk
}

How to cite this paper: Corazon, S.S., Olsen, L.J., Olsen, A.-M. and Sidenius, U. (2019) Nature-Based Therapy for People Suffering from Post-Concussion Syndrome-A Pilot Study. Health, 11, 1501-1517. https://doi.org/10.4236/health.2019.1111113

Received: October 9, 2019

Accepted: November 12, 2019

Published: November 15, 2019

Copyright (c) 2019 by author(s) and Scientific Research Publishing Inc. This work is licensed under the Creative Commons Attribution International License (CC BY 4.0).

http://creativecommons.org/licenses/by/4.0/

cc) (†) Open Access

\begin{abstract}
Background: Approximately $10 \%$ - 15\% of people diagnosed with a concussion develop post-concussion syndrome (PCS), in which mental fatigue is a dominating symptom. PCS has major consequences for the individuals diagnosed, and society as a whole. Objective: The objective of the pilot study was to investigate whether a nature-based therapeutic (NBT) intervention would be suitable for ameliorating the symptoms experienced by people with PCS, especially mental fatigue. Method: Eight participants diagnosed with PCS took part in a NBT programme, which consisted of weekly two-hour sessions over the course of eight weeks. The participants' level of mental fatigue was measured on the Mental Fatigue Scale (MFS) before and after the intervention. An analogue scale inspired by the EuroQol-visual analogue scales (EQ-VAS) was used to measure immediate self-perceived feeling of health/ well-being before and after individual sessions. A semi-structured interview was held with each participant after the intervention. The interviews and logbooks were analysed through content analysis, which entails several steps in a spiral-like process, from reading and re-reading the transcripts to forming units of meaning, which were then grouped into sub-categories and categories for further analysis. Result: The MFS showed a significant decrease in mental fatigue and large effect size. The participants' self-assessed health/ well-being on the analogue scale showed an increase from the beginning to the end of each session. The analysis of the interviews revealed that the participants experienced the sensory stimuli and exercises in the natural environment as motivating and meaningful, even when they were challenging. Further, they found the psycho-educational aspects transferable to everyday life. Conclusion: The results support that NBT can have potential in the rehabilitation of PCS, by lowering mental fatigue and improving health and
\end{abstract}


well-being. The NBT was further found to be experienced as enjoyable and motivating with good transferability to everyday life.

\section{Keywords}

Mild Traumatic Brain Injury, Concussion, Mental Fatigue, Ecotherapy, Nature-Based Rehabilitation

\section{Outline}

- At present, there is no formalized treatment for post-concussion syndrome (PCS).

- Nature-based therapy might hold potential in alleviating mental fatigue, a core symptom in PCS, by promoting soft fascination.

- The study shows promising results concerning alleviating mental fatigue and increasing the experience of health and well-being for people suffering from PCS.

\section{Introduction}

The research on mild traumatic brain injury (MTBI), also known as concussion, is receiving increased attention in research [1] [2]. It is difficult to estimate how many people are affected by MTBI, as many cases are thought not to be reported [3]. However, MTBI is estimated to be the prevalent condition in the reports on traumatic brain injuries [3] [4], which are estimated to affect 50 million people per year worldwide [5]. In Denmark, where the pilot study took place, it is estimated that approximately 25,000 Danes experience MTBI per year [6].

MTBI is caused by a blow to the head or another incident which causes the brain to hit the inside of the skull. The incident can cause microscopic injuries of the brain tissue along with physiological imbalances, mainly in the brain's sensory-motor systems [7]. The prevailing physical symptoms are mental fatigue, concentration difficulties, headaches, dizziness, nausea, increased sensitivity to light and sound, sleep disturbances and in some cases temporary loss of memory concerning the event [6] [7].

In most cases of MTBI, the symptoms disappear within a few weeks. However, in $10 \%-15 \%$ of the incidents, the symptoms persist [8]. If the symptoms persist, the condition is classified as post-concussion syndrome (PCS) [9]. However, the criteria have been criticized for being poorly defined [10]. The Danish adaption of the International Classification of Primary Health Care (ICPC) defines PCS as a persistence of the symptoms mentioned above for more than three months [6]. The diagnosis is based on patient self-records and clinical findings. The precise mechanisms for developing PCS are still largely unknown, but socio-psychological, genetic, biological and individual factors all seem to play a role in the risk of developing PCS after MTBI [11]. 
Apart from the persistent symptoms from the MTBI, people suffering from PCS can also experience emotional and behavioural changes such as mood swings, increased irritability, sensitivity to stress and lack of initiative [8]. Family and social life can also be affected, as the symptoms can be triggered in any situation requiring even small amounts of mental and/or physical effort. On the socioeconomic level, PCS is related to prolonged sick leave and unemployment [12] [13].

Mental fatigue is the core symptom of PCS, categorized by a rapidly occurring and pronounced feeling of drain of mental energy, after even moderate mental activity. It leads to concentration difficulties and often has a long recovery time. Further, it can trigger a range of emotional, cognitive and sensory processing symptoms such as mood swings, irritability, lack of initiative, stress sensitivity, slowness of thinking and memory problems, sensitivity to light and noise and headaches [8].

There is ongoing research into the causes of PCS-related mental fatigue and the appropriate treatments [5]. A predominant theory is that the injury causes imbalances in the brain's neurotransmitters [7] [8]. This theory is supported by studies showing that medicine stabilizing specific neurotransmitters can reduce mental fatigue, but not cure it [14]. Mindfulness-based stress Reduction (MBSR) as well as cognitive behavioural therapy has been found to have effects [15] [16]. The recommended coping strategies involve keeping a calm pace in one's everyday activities, planning ahead, taking frequent little breaks as well as learning the signs of oncoming mental fatigue. Aerobic, sight and balance training have also been found to have a positive effect on the different symptoms of PCS [17].

\section{Nature-Based Therapy}

The term nature-based therapy (NBT), also known as eco-therapy, covers a range of different interventions and treatment approaches, all of which integrate the natural environment into the treatment [18]. The different activities and experiences found in the natural environment, which can range from a therapy garden to a remote wilderness, are used to enhance the therapeutic effects of the given treatment for the specific group.

A common theoretical foundation for nature-based therapy is Attention Restoration Theory (ART), which was developed by the cognitive psychologists Steven and Rachel Kaplan [19]. ART is based on two different attention systems: voluntary and involuntary attention. Voluntary attention, also known as directed attention, is a time-limited, mentally demanding capacity used to focus our attention and concentrate on something, for example, a work task, while excluding disturbing external and internal stimuli. When the resource is depleted, it can lead to a feeling of mental fatigue. Involuntary attention, on the other hand, is an unlimited, less mentally demanding resource whereby one spontaneously becomes fascinated by something. The Kaplans' hypothesis was that 
natural environments with specific characteristics were especially suited to promote a specific type of involuntary attention named "soft fascination". This type of attention is characterized by a relaxed state of mind in which one is gently absorbed and fascinated by the occurring stimuli. The hypothesis behind ART is that being in a state of soft fascination can provide restoration from mental fatigue arising from the use of directed attention. This hypothesis has subsequently been validated by research [20]. The optimal environment for attention restoration should: 1) provide a feeling of "being away"; 2) provide a feeling of "extension" so it feels like a coherent, easily interpretative world in itself; 3) contain various calm sensory stimuli to awake fascination; and 4) be compatible with the resources and preferences of the individual [19].

The potential of natural environments to restore mental fatigue-mental fatigue being the core element of PCS-led to the development of the pilot project. Further, we see similarities between the conventional sensory training and the implicit training of the senses in natural environments containing the components mentioned above. It is therefore hypothesized that these kinds of natural environments would be suitable for sensory training of people with PCS.

The psycho-education and/or psychotherapy in NBT integrates metaphor and mirroring in the environment. The more abstract learning is thereby given an embodied or physical dimension which is thought to support the learning [21] [22].

A systematic literature search was carried out to obtain knowledge of previous research on nature-based interventions for PCS. The following databases were used: Ovid, Cab Abstract, Web of Science, Scopus, PsychINFO and PubMed. The search string combined different terms for head trauma with different terms for NBT. The search resulted in 23 articles, none of them involving a nature-based intervention for PCS. Therefore, to the authors' knowledge, there is no previous published research in the field.

The objective of the pilot study was to investigate whether a nature-based therapeutic intervention would be suitable for ameliorating the symptoms experienced by people with PCS, especially mental fatigue, and further improve their health and well-being.

\section{Method}

\subsection{Intervention}

The NBT intervention was based on the Nacadia ${ }^{\circledR}$ NBT Concept, which integrates sensory-motor experiences and activities in nature with elements from mindfulness-based stress reduction and psycho-education within cognitivebehavioural therapy [18]. The Nacadia NBT concept was used as a framework to plan the programme for the specific group.

The sensory-motor experiences in the natural environment were employed in exercises with different or sometimes overlapping aims: one was to promote the feeling of soft fascination; another was to train and challenge the participants' 
tolerance of sensory stimulation. Progressive relaxation and guided body scans lying or sitting outside in the environment were also used to make the participants aware of bodily tensions and learn to release them. The psycho-education used mirroring and metaphors in the natural environment to illustrate the psycho-educational content and help the participants understand and cope with the consequences of the PCS.

The intervention lasted eight weeks, with weekly two-hour sessions. It took place in a nature reserve called Luknam, which includes a diverse forest, meadows and a large lake. The environment was chosen based on the characteristics of a restorative natural environment described in the ART theory [19].

The gathering point and base for each session was a firepit outside a cottage within the area. The cottage is normally used by a daycare centre in the area, but permission was given to use it for the intervention. The cottage had toilet facilities and provided shelter in case of rain.

Each session had the same structure, starting with a gathering around the fire, where the participants were given the chance to share their thoughts and experiences since the previous session. Then the day's session was introduced. Each session involved a challenging activity in the form of sensory-motor stimulation and/or reflection on nature metaphors, based on a psycho-educative element. The challenging activity was followed by a relaxing and soft sense-stimulating activity, which could be lying or sitting in the environment with or without a guided body scan (Figure 1). The participants shared their reflections and experiences on the walk back from an exercise or in a group around the firepit. The session was rounded off around the firepit with instructions for home exercises based on the session (The full NBT programme for PCS, in Danish, can be acquired by contacting the corresponding author).

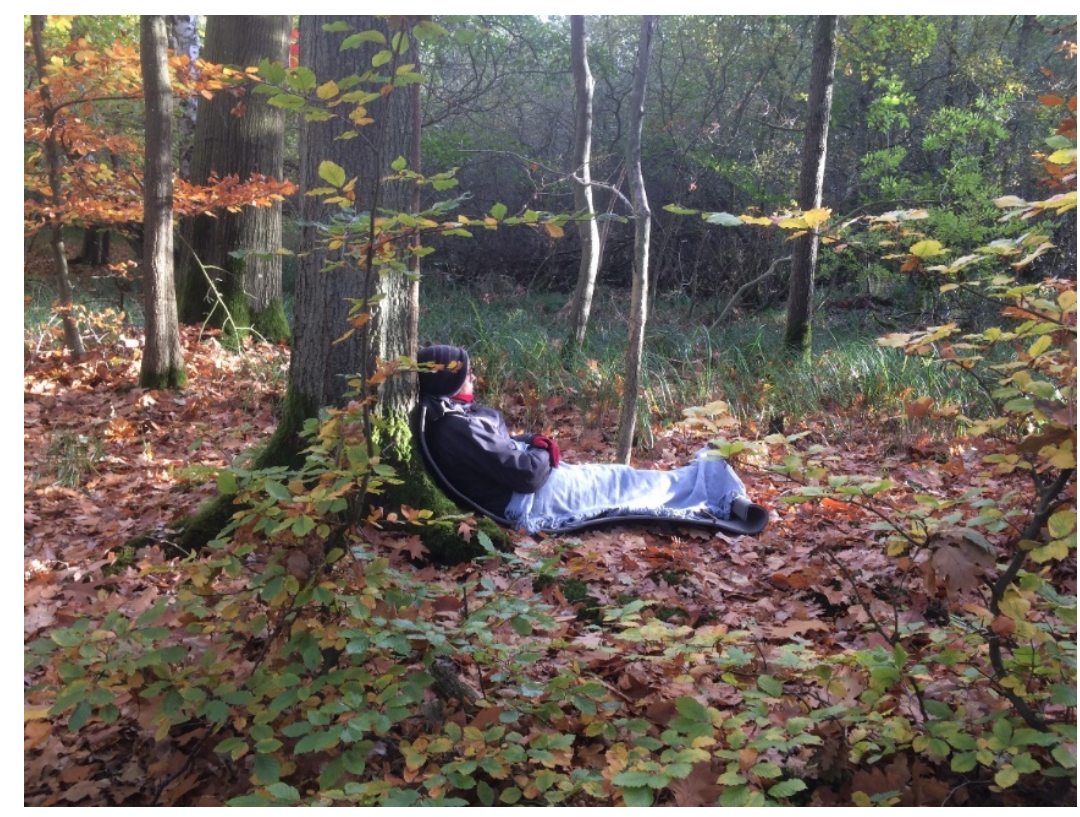

Figure 1. Relaxing activity. 


\subsection{Recruitment}

The participation limit was set at eight participants, as previous projects on NBT had shown this to be a suitable group size [18]. The participants were recruited by contacting coordinators dealing with brain injuries and sick leaves at job centres in municipalities near the intervention location. The coordinators referred interested people to the project. A call for participants was also posted on Facebook. Potential participants were first contacted by phone, when they were briefly introduced to the intervention, and an appointment for an interview was made. All those referred agreed to participate, and the recruitment process was ended when eight people had signed up for participation. The two therapists (a psychomotor therapist/nurse, MSc's in health-promoting natural environments and NBT therapy) in charge of the sessions conducted the interviews. The interviews were held at an indoor office setting in Copenhagen, and lasted approximately one hour. They were recorded with the participants' consent. The interviews served as an introduction to the NBT intervention and provided background information on the participants. The participants had all been diagnosed with PCS by a general practictioner, neurologist or neuropsychologist before they were enrolled in the intervention. They were informed about the option to withdraw from the intervention and/or withdraw permission to use their data at any time during the project, and a written consent form was signed.

The intervention was free of charge for the participants, except for transport to the location.

\subsection{Data Collection}

The study's aim was operationalized into three research questions.

Does the NBT intervention have an effect on the mental fatigue experienced by the participants with PCS?

Do the NBT sessions have an effect on the participants' self-perceived state of health and well-being?

What is the participants' experience of the NBT intervention and the activities?

To investigate the research questions the study deployed a mixed-method design. It included the validated Mental Fatigue Scale questionnaire, which was filled out before and after the intervention. A scale inspired by the EuroQol-visual analogue scale (EQ-VAS) was used at the beginning and end of each session. Semi-structured interviews were conducted after the intervention, and each participant had a logbook in which they could note their experiences and reflections. The logbook was collected at the end of the intervention and returned to the participants after the analysis.

The Mental Fatigue Scale (MFS) was developed and validated specifically for assessing the level of mental fatigue after a mild traumatic brain injury [23]. It consists of 15 questions, which are rated on a 7-point scale from 0 to 3 with 0.5 intervals, including 4 statements ranging from not at all (0), sometimes (1), 
mostly (2), to always (3). The questions concern self-perceived general fatigue, lack of initiative, mental fatigue, mental restoration, concentration and/or memory difficulties, stress sensitivity, increased emotionality, irritability, light and/or sound sensitivity and sleep disturbances. The total score is related to different levels of mental fatigue (see Table 1).

Table 1. Levels of mental fatigue on the MFS.

\begin{tabular}{cc}
\hline Level of mental fatigue & MFS Score \\
\hline No mental fatigue & $0-10$ \\
Light mental fatigue or risk of mental fatigue & $11-14$ \\
Moderate mental fatigue & $15-20$ \\
Severe mental fatigue & $>20$ \\
\hline
\end{tabular}

The pre-post scores from the MFS were analysed by a paired sample $t$-test (two-tailed), based on the nul hypothesis (no difference between pre- and post-scores). The distribution of the data set was analysed by Shapio-Wilk Test.

The visual analogue scale was inspired by the EuroQol-visual analogue scales (EQ-VAS), which ranges from 0 (worst possible health) to 100 (best possible health), which is a cognitive undemanding and easily readable scale [24]. It was adjusted to have the endpoints: worst possible immediate feeling of overall health and well-being (0), to best possible immediate feeling of overall health and well-being (100). The scale was used as an indicator of change in momentary experiences of health and well-being from the beginning to the end of the sessions. In order for the participants not to compare their later scores with their score at the beginning, a separate paper with the scale was handed out at beginning and the end of the session.

A semi-structured interview was held after the intervention. It lasted approximately 45 - 60 minutes and took place in an office indoors in Copenhagen. The purpose of the interview was to obtain knowledge of the experiences of the participants, both during the NBT intervention as a whole and during the individual activities. The interviews were recorded with the participants' consent and later transcribed. The logbooks were read with the participants' consent and integrated into the analyses.

The interviews and logbooks were analysed through content analysis [25], which entails several steps in a spiral-like process, from reading and re-reading the transcripts to forming units of meaning, which are then grouped into sub-categories and cateogies, for further analysis.

\section{Quantitative Results}

\subsection{Completion and Background Information}

All eight participants completed the intervention (the criterion for completion was attendance in at least four sessions). The attendance varied from session to session, and the overall attendance for all eight sessions was $80 \%$. 
The participants consisted of six women and two men, with a mean age of 38.5, ranging from 25 - 59 years. The participants had suffered from PCS from between four months to six years. Seven of the participants lived with their spouse and/or children and one lived alone. Six were on full-time sick leave, one was on part-time sick leave and one had resumed work. They had previously tried other public and/or private rehabilitation initiatives.

\subsection{Results on Mental Fatigue Scale}

Figure 2 shows the individual participant's pre-post scores on the mental fatigue scale. The mean score on the mental fatigue scale before the intervention was 23.4 points, which corresponds to severe mental fatigue (Table 1). The mean score decreased to 20.6 points after the intervention, which almost corresponds to moderate mental fatigue (Table 1).

The mean difference in pre-post scores of -2.8 points was found to be statistically significant $(\mathrm{p}<0.05)$, with a large effect size (0.96) (Table 2).

Table 2. Participants' pre-post scores on MFS: Mean value, standard deviation and significance level.

\begin{tabular}{cccc}
\hline Mean & Standard dev. & Significance & Effect size \\
\hline-2.8 & 2.94 & 0.03 & 0.96 \\
\hline
\end{tabular}

The Shapio-Wilk test showed normal distribution of the mean differences within the sample. However, there were large individual differences in the scores; two participants did not change from before to after the intervention, whereas the remaining six participants experienced a decrease between 0.5-8.5 points. None of the participants experienced an increase on the mental fatigue scale (Figure 2).

\section{Individual results on mental fatique scale from before to after the intervention}

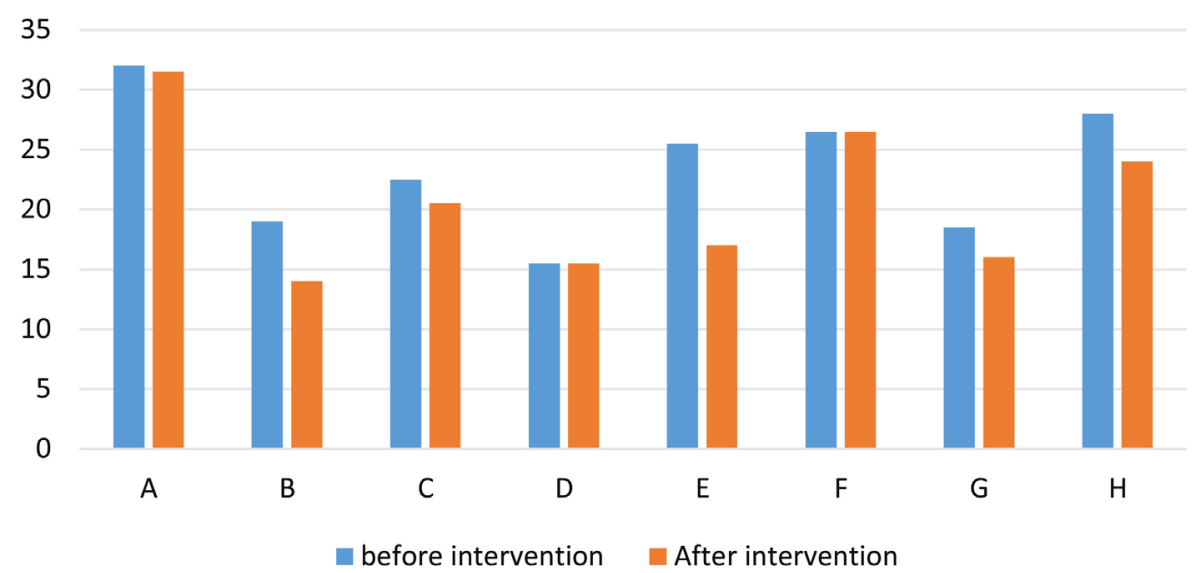

Figure 2. Overview of the individual participants' score on the MFS from before to after the intervention. 


\subsection{Results on Analogue Scale}

Figure 3 shows the participants' mean differences in the scores on the analogue scale from the beginning to the end of each session. There were large individual variations in how the participants estimated their immediate health/well-being; some had large variations in their scores from the beginning to the end of each

\section{Mean difference from beginning to end of each session} on health/well-being

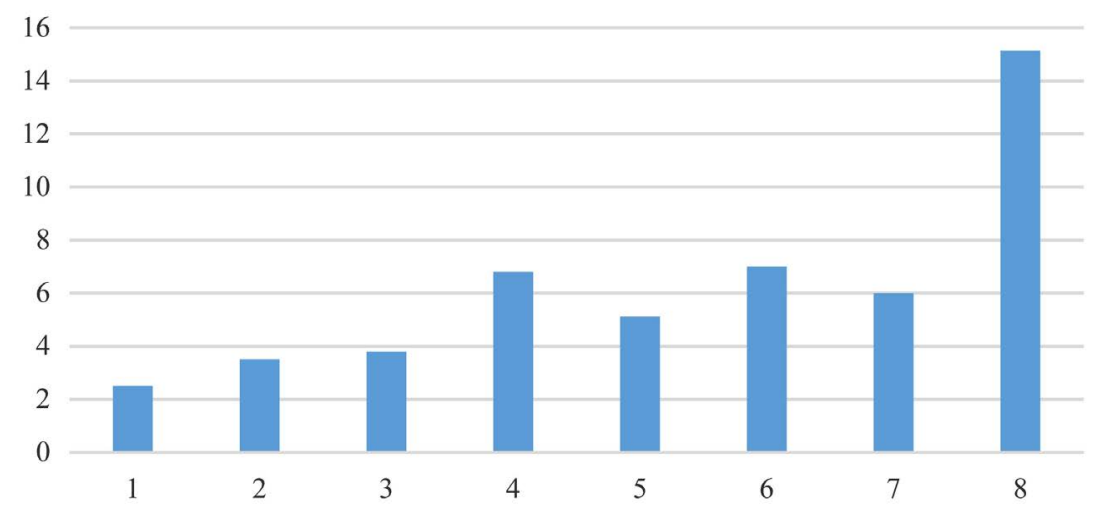

Figure 3. Mean difference across participants in immediate feeling of health and well-being scores from the beginning to the end of each session (8 sessions in total).

session, while others only showed small variations. The 50 individual start and end scores mainly showed a positive effect of the sessions; $68 \%$ showed an increase from the beginning to the end of the session, whereas $14 \%$ showed a decrease, and $16 \%$ had the same scores at the beginning and end of the session. There was no detected pattern in who reported increase or decrease in the individual sessions.

\section{Qualitative Results}

The units of meaning, related to the research questions, were marked and divided into sub-categories and categories, which all together formed three different overarching themes across categories: rehabilitation in a natural environment; doing NBT activities; and mirroring and metaphors in NBT psycho-education (Table 3) The content of the themes will be presented in the following section.

\subsection{Rehabilitation in a Natural Environment}

In their narratives, the participants gave positive values to the stimuli they experienced in the natural environment. They found the natural stimuli motivating, even when they experienced them as challenging. Some commented on the difference between experiencing an intervention indoors, which they all had tried, to being outdoors, which they preferred. Some of the interviewees recounted how they had more mental energy to take in the different exercises because they were outside in nature, where the acoustics were easier to cope with. 
Table 3. Content analysis of the qualitative data.

\begin{tabular}{|c|c|c|c|}
\hline Research questions & Units of meaning & Sub-categories & Categories \\
\hline $\begin{array}{l}\text { Effect on mental } \\
\text { fatigue }\end{array}$ & $\begin{array}{l}\text { - } \text { Sensory stimulation } \\
\text { related to PCS (all } \\
\text { senses) } \\
\text { - PCS Symptoms } \\
\text { - (all symptoms) }\end{array}$ & $\begin{array}{l}\text { - Experiencing nature } \\
\text { stimuli } \\
\text { - Experienced symptom } \\
\text { relief } \\
\text { - Experienced symptoms } \\
\text { worsening }\end{array}$ & $\begin{array}{l}\text { - Appraisal and } \\
\text { threshold for } \\
\text { stimuli } \\
\text { - Change in PCS } \\
\text { symptoms }\end{array}$ \\
\hline $\begin{array}{l}\text { Effect on } \\
\text { self-perceived state of } \\
\text { health and well-being }\end{array}$ & $\begin{array}{l}\text { - Sensory stimulation } \\
\text { related to well-being (all } \\
\text { senses and all narratives } \\
\text { on well-being) } \\
\text { - Narratives on nature } \\
\text { relation }\end{array}$ & $\begin{array}{l}\text { - Relaxation } \\
\text { - Fascination } \\
\text { - Accept } \\
\text { - Optimism } \\
\text { - Increased insights }\end{array}$ & $\begin{array}{l}\text { - Increased } \\
\text { well-being by } \\
\text { nature stimuli } \\
\text { - Changed } \\
\text { self-perception } \\
\text { regarding PCS } \\
\text { - Psychological } \\
\text { support from } \\
\text { nature }\end{array}$ \\
\hline $\begin{array}{l}\text { Experience of the } \\
\text { NBT intervention and } \\
\text { the activities }\end{array}$ & $\begin{array}{l}\text { - Motivation } \\
\text { - Sensations } \\
\text { - Experiences } \\
\text { - Challenges, barriers and } \\
\text { strain } \\
\text { - State of mind } \\
\text { - The others/group setting }\end{array}$ & $\begin{array}{l}\text { - Being in the present } \\
\text { - Moment } \\
\text { - Indontal strain } \\
\text { - Being with other people } \\
\text { - transferability }\end{array}$ & $\begin{array}{l}\text { - Valuing nature } \\
\text { - Body versus mind } \\
\text { - New coping tools } \\
\text { - Group support }\end{array}$ \\
\hline Themes & $\begin{array}{l}\text { Rehabilitation } \\
\text { in a natural environment }\end{array}$ & Mirroring and metaphors & Doing NBT activities \\
\hline
\end{tabular}

"Indoor rooms have acoustics, and the outdoors doesn't. The acoustics in rooms affect me quite a bit. So it's been nice not to be in a room. I ve been to mindfulness and yoga and all sorts of things, but I couldn't do it for long because either the instructors' voices were too loud, or there were too many people, or the acoustics were too bad. Also just feeling the cold, the warmth, the smells... it feels more real when you' re outside. It also makes you calmer somehow."

The absence of disturbing acoustic stimuli also made it easier for some of the participants to take part in and benefit from group discussions, something they usually found very mentally fatiguing.

"For me, conversation is one of the worst things. But somehow it's easier in a forest."

A recurrent narrative around being in the natural environment was the experience of being present in the moment, which was described with words like grounding, centring, relaxing, calming and soothing (Figure 4).

"If it's a little wild [nature], then it's almost as if your brain is just present in that place, at least I notice that I can get settled more easily, because there are so many interesting things to observe."

\subsection{The NBT Activities}

The activities involving soft sensory stimulation such as lying on the forest floor, walking slowly or watching the waves on the lake, were generally found to have a 


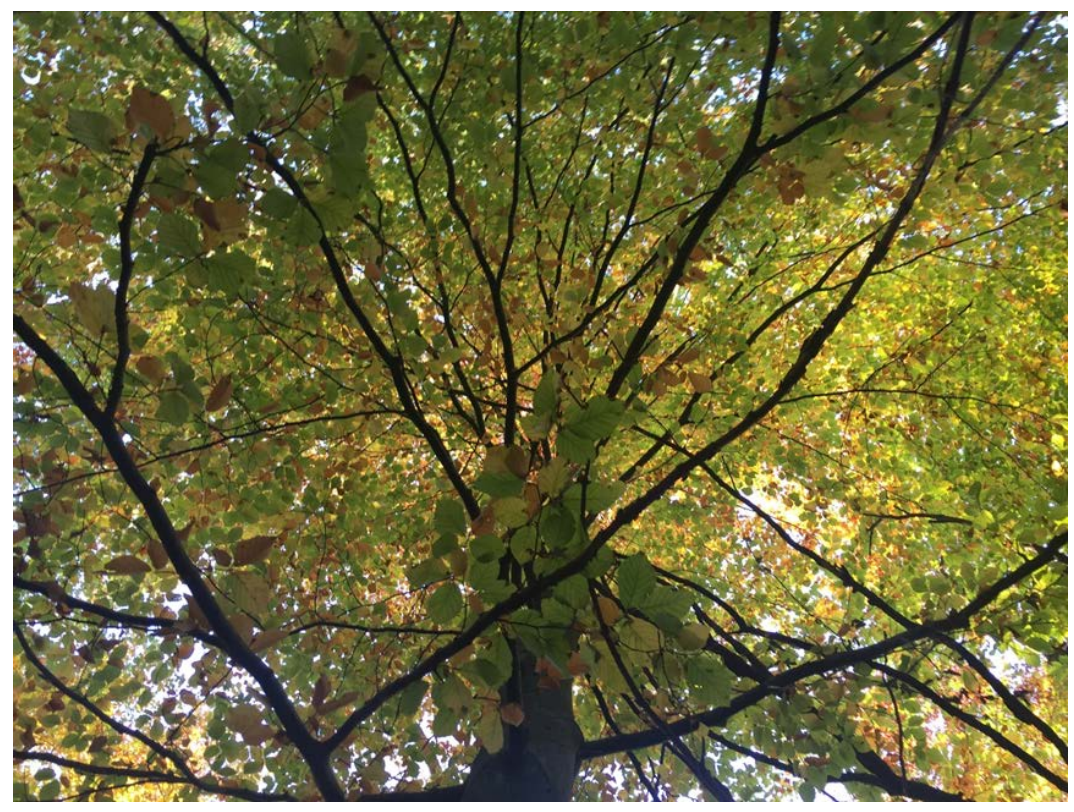

Figure 4. Lying on the forest floor looking up at the crown of the tree.

positive effect, even when the sensory stimulation was reported to be challenging. However, some of the psycho-educational activities, which required more mental effort, were found to be too mentally fatiguing for some of the participants.

"When you have a concussion, there's a lot going on in our brains and intellectually, and we lack the grounding and calm in the body and the sense of fullness and comfort. I lack that feeling of calm and comfort, and some of these exercises have given me that feeling, but there are also some exercises that haven't, especially if they' re linked to something intellectual; then they don't give me the comfort I need."

Several participants found that their tolerance of sensory stimuli increased by doing the exercises, and also helped them relax. This shows the combined physical and mental potential of doing the exercises in a natural environment.

"The visual exercise brought me down to a state where I felt a deeper calm than $P$ ve felt for a long time, and a much greater awareness of the things around me when we did it again. I found I got a bit seasick from all that moving water, and that's one of the effects of my concussion. Sometimes I almost lose my balance if I look at something that's moving all the time. But I felt a lot calmer when we did it a second time, and I thought, Wow, my nervous system must have calmed down, since I can keep looking at that water now."

The participants seemed to have a greater tolerance of PCS symptoms during and after the exercises because they were enjoying the natural environment, as expressed in the following quotes:

"Absolutely fantastic relaxation. I usually get irritated, but in these surroundings it was perfect. It was nice to feel the eyes relax. I got a little headache from it, but it was lovely." 
"Got a sore neck in the evening, but otherwise no major problems after the lovely day in the forest."

A few of the activities were found to be too demanding and mentally straining for the participants on different levels. This was especially the case with the psycho-educational activities, as mentioned in the previous quote. One participant found one of the activities too distressing on a personal level. It was an exercise of sensing a tree while blindfolded with the help of another participant. The aim was to awaken other senses than sight, and increase the group feeling. The other participants found the exercise very helpful, but the reaction from one of the participants highlights the importance of always paying attention to different personal boundaries and emphasizing the freedom not to participate.

"I thought it was super-uncomfortable, but I didn't want to say I wouldn't do it. I thought the idea of finding your own tree was good, but I couldn't relax at all. I couldn't let go of the feeling that I might hurt myself."

The participants shared how different exercises had helped them understand the psycho-educational content better, as illustrated by the quote below.

"Your exercises let me put some of the concepts I was given at the Centre for Rehabilitation of Brain Injury into practice. Suddenly they made a bit more sense-oh, so that's what they meant. By standing out there in the grass, instead of a psychologist saying, Try to live a little in the present."

People with PCS experience an ongoing battle to reduce sensory stimuli in their everyday lives. The experience of sensory stimuli as being enjoyable and in some cases relaxing was expressed as a major insight for the participants. Along with the psycho-education it led to changes in coping strategies. Whereas before their preferred strategy when feeling mentally fatigued might have been withdrawing from the world, they could now use pleasant sensory stimulation, for example, a walk in nature, to avoid distressing thoughts when trying to relax. The transferability of the exercises to everyday life therefore seemed to be aided by being physically engaged in a natural environment.

\subsection{Mirroring and Metaphors in NBT Psycho-Education}

The integration of physically present nature metaphors seemed to provide the intended support to take in the psycho-educational elements. An example from a session is the story of how oak trees let go of some of their branches in storms in order to stay rooted and not fall over. This story was told as an introduction to individual reflection on what the participants have had to let go of due to PCS, and maybe was still struggling to let go of. The metaphor was taken further to reflect on which branches (values and important areas in their life) were vital to keep and nourish, and which new branches might be growing. The participants reflected while sitting against an oak tree they had chosen.

"That thing with the oak tree, where we had to let go of some our branches, that was an eyeopener... [laughter]. I thought, It's actually going pretty well. It made me optimistic. Maybe I had got rid of some branches. There was a realiza- 
tion that that was necessary in order to move forward. That oak tree that grows some new branches, new possibilities."

The participants also spontaneously used nature and natural elements as a mirror, and found this helpful, as illustrated by the following quote.

"Today I found a mushroom, looked at it and felt the softness that I recognize in myself these days. I turned it over and became fascinated by its underside and thought about what was really important to me and my new approach to how I should live my life. Instead of being a bit overwhelmed by all the directions life can take, I thought about it in terms of new possibilities (both positive and negative), which I think $P$ ve become better at seeing and feeling in order to move forward and not get stuck in a rut. The holes of life in the mushroom and its paths forward in life. Accepting ourselves. Looking at opportunities instead of limitations. Thinking positive thoughts every day."

Several of the participants described how, during the intervention, they had become conscious of how living with PCS had affected their sense of self, as they had become more negative and/or felt greater need for control. In some cases, this newfound awareness of the personal effects of PCS led to efforts to make emotional and/or behavioural changes. For example, one participant decided to resume more outgoing activities because it was important for their quality of life. Another reflected on their relation to their spouse, which had been affected by the negativity around the symptoms, and decided to work on a more positive attitude regarding letting go of some of the need for control. Here the positive impact of being outdoors in a natural environment played an important role.

"It's been lovely to get out [...] and feel calmer in my body and mind. I think the main thing has been getting a slightly different perspective on my condition and getting out into the woods, that helps the mind the most, I think [...] getting out in the woods calms your thoughts down a bit, so you feel a little more empty or free in your body, a bit more grounded, which takes the edge off some of the bad feelings and thoughts. Yes, it calms the body and the bad thoughts."

\section{Discussion}

The significant decrease on the mental fatigue scale indicates that the NBT intervention has potential to alleviate one of the main symptoms related to PCS. However, the dataset was quite small and two of the participants did not decrease on the scale. Also, the study lacked a control group, so it cannot be excluded that the improvement was caused by time itself. Studies have shown that the spontaneous improvement of symptoms from mild traumatic brain injury usually happens within the first couple of months; hereafter the symptoms take on a more chronic character [26]. This corresponds with the results of a study on PCS with a control group, which found no spontaneous improvement in the control group over the course of the intervention [27]. Six of the participants in the present study had suffered from PCS for more than a year, while two of them had suffered from it between four and six months. We therefore assume that any 
spontaneous improvement during the intervention would be modest. However, the improvement could also have been caused by factors outside the intervention, as these were relatively short weekly sessions.

The interviews and logbooks support the assumption that the intervention caused the improvement on the MFS, as the participants related the improvement of PCS symptoms to the intervention. It is further supported by the results from the analogue scale used after each session. These show a steady increase of the effect on immediate health and well-being of the individual sessions.

The interviews and logbooks gave us insight into the personal experiences behind the scores on the analogue scale. For example, one participant scored very low at the beginning of the last session, and very high at the end. The logbook revealed that the participant had had a very mentally fatiguing day prior to the session-hence the low score at the beginning-and felt the session had restored the mental resources at the end. This case illustrates that natural environments can accommodate the restoration of mental fatigue, as proposed in Attention Restoration Theory [19] [28]. Further, did the participants' narratives on their state of mind in nature, as being calm, meditative and absorbed, correspond to a shift in attention towards soft fascination, described by the ART theory, as the mechanism that provides mental relief from attention fatigue [28].

Another participant commented on the surprise of not being mentally fatigued after the sessions, but feeling the same state of well-being as on arrival, since most activities normally led to mental strain. For this participant, it was positive that the level of well-being remained the same at the beginning and end of a session. This case highlights the importance of also collecting qualitative data, as no change in quantitative measures would usually be interpreted as no effect found. From a participant perspective, the analogue scale can be a tool for self-monitoring of strain versus ease/well-being during activities. This was not our intention by introducing the scale, but an unexpected benefit for some of the participants that they could use to cope with the symptoms of PCS.

Based on the logbooks and interviews, both the spontaneous and guided mirroring in nature, as well as metaphors related to the physical environment seemed to be appropriate and beneficial tools for introducing psycho-educational aspects, with less mental strain. In many cases, the psycho-education was found more easily accessible due to the physically present metaphors, such as the oak tree, which is in line with literature on the therapeutic potential of NBT [21] [22], where the use of metaphors is a vital aspect.

However, taking in psycho-education is difficult for people suffering from PCS, as it requires mental energy, and in some cases, the participants found it too mentally challenging. Finding the right dose of psycho-education is difficult with a group intervention compared to individual therapy. People suffering from PCS commonly find conversation mentally fatiguing. It was therefore surprising for both the therapists and the participants that the participants mostly enjoyed-some even encouraging-group conversations and sharing their expe- 
riences with the others. Here, the natural environment seemed to play an important role, as it was experienced as having less disturbing and stressful stimuli compared to an indoor room, leaving more mental energy for the conversation itself. The setting around a firepit was experienced as lowering the mental strain, as it was a gathering point for visual attention, which limited eye contact and allowed silent periods to occur without awkwardness. Nature as a collective third party is emphasized as a cornerstone in much of the literature on NBT [18] [21] [29]. The participants' experiences support this therapeutic potential of doing therapy outside.

\section{Limitations}

A fundamental limitation in the interpretation of the results lies in the lack of control group and a small sample. Therefore, the results should only be seen as indications which need to be tested in a larger sample with a control group, possibly as a cross-over study where the participants act as their own control, so everybody is offered treatment.

Another limitation concerns the collection of data, which was carried out by the therapists conducting the sessions. As some of the participants had sight and reading difficulties due to their PCS, the therapists had to read the questions in the MFS questionnaire out loud and mark the answers. This lack of compliance with the arm-length principle in research could have biased the results.

The participants experienced a lack of rehabilitation offers and felt overlooked in the healthcare system; therefore, participating in an intervention and receiving attention could in itself have imposed a placebo effect, which could have been increased by the fact that the recruitment was based on volunteering.

\section{Conclusion}

The results support that NBT can have potential in the rehabilitation of PCS by lowering mental fatigue and improving well-being. The NBT was further found to be experienced as enjoyable and motivating with good transferability to everyday life.

\section{Conflicts of Interest}

The authors declare no conflicts of interest regarding the publication of this paper.

\section{References}

[1] Cassidy, J.D., Cancelliere, C., Carroll, L.J., Cote, P., Hincapie, C.A., Holm, L.W., Hartvigsen, J., Donovan, J., Nygren-de Boussard, C., Kristman, V.L., et al. (2014) Systematic Review of Self-Reported Prognosis in Adults after Mild Traumatic Brain Injury: Results of the International Collaboration on Mild Traumatic Brain Injury Prognosis. Archives of Physical Medicine \& Rehabilitation, 95, 132-151. https://doi.org/10.1016/j.apmr.2013.08.299

[2] Maas, A.I., Menon, D.K., Steyerberg, E.W., Citerio, G., Lecky, F., Manley, G.T., Hill, 
S., Legrand, V., Sorgner, A., et al. (2015) Collaborative European NeuroTrauma Effectiveness Research in Traumatic Brain Injury (CENTER-TBI): A Prospective Longitudinal Observational Study. Neurosurgery, 76, 67-80. https://doi.org/10.1227/NEU.0000000000000575

[3] Katz, D.I., Cohen, S.I. and Alexander, M.P. (2015) Mild Traumatic Brain Injury. Handbook of Clinical Neurology, 127, 131-156. https://doi.org/10.1016/B978-0-444-52892-6.00009-X

[4] Feigin, V.L., Theadom, A., Barker-Collo, S., Starkey, N.J., McPherson, K., Kahan, M., Dowell, A., Brown, P., Parag, V., Kydd, R., et al. (2013) Incidence of Traumatic Brain Injury in New Zealand: A Population-Based Study. Lancet Neurology, 12, 53-64. https://doi.org/10.1016/S1474-4422(12)70262-4

[5] Maas, A., Menon, D.K., Adelson, P.D., Andelic, N., Bell, M.J., Belli, A., Bragge, P., Brazinova, A., Buki, A., Chesnut, R.M., et al. (2017) Traumatic Brain Injury: Integrated Approaches to Improve Prevention, Clinical Care, and Research. Lancet Neurology, 16, 987-1048. https://doi.org/10.1016/S1474-4422(17)30371-X

[6] Pinner, M., Børgesen, S.E., Jensen, R., Birket-Smith, M., Gade, A. and Riis, J. (2016) Konsensusrapport om commotio cerebri (hjernerystelse) og det postcommotionelle syndrome (in Danish) Videnscenter for Hjerneskade.

https://hjernerystelsesforeningen.dk/wp-content/uploads/2016/03/2003Pinner-mug ge-konsensus.pdf

[7] Blennow, K., Hardy, J. and Zetterberg, H. (2012) The Neuropathology and Neurobiology of Traumatic Brain Injury. Neuron, 76, 866-899. https://doi.org/10.1016/j.neuron.2012.11.021

[8] Johansson, B. and Rönnbäck, L. (2014) Long-lasting mental fatigue after traumatic brain injury. In: Sadaka, R., Ed., Traumatic Brain Injury, Chapter 2, Elsevier, Amsterdam, 491-511. https://doi.org/10.5772/57311

[9] World Health Organization (2016) International Classification of Deceases, Version 10, F07.81 Postconcussional Syndrome. https://icd.who.int/browse10/2016/en

[10] Polinder, S., Cnossen, M.C., Ruben, G.L., Real, R., Covic, A., Gorbunova, A., Voormolen, D.C., Master, C.L., Haagsma, J.A., Diaz-Arrastia, R. and Steinbuechel, N. (2018) A Multidimensional Approach to Post-Concussion Symptoms in Mild Traumatic Brain Injury. Frontiers of Neurology, 9, 1113. https://doi.org/10.3389/fneur.2018.01113

[11] Wilde, E.A., Barnes, A., Hanten, G, Mendez, D., McCarthy, J. and Levin H.S. (2015) Prevalence and Predictors of Poor Recovery from Mild Traumatic Brain Injury. Journal of Neurotrauma, 32, 1488-1496. https://doi.org/10.1089/neu.2014.3555

[12] Palm, S., Rönnbäck, L. and Johansson, B. (2017) Long-Term Mental Fatigue after Traumatic Brain Injury and Impact on Employment Status. Rehabilitation Medicine, 49, 228-233. https://doi.org/10.2340/16501977-2190

[13] Langlois, J.A., Rutland-Brown, W. and Wald, M.M. (2006) The Epidemiology and Impact of Traumatic Brain Injury: A Brief Overview. Journal of Head Trauma Rehabilitation, 21, 375-378. https://doi.org/10.1097/00001199-200609000-00001

[14] Wylie, G.R. and Flashman, L.A. (2017) Understanding the Interplay between Mild Traumatic Brain Injury and Cognitive Fatigue: Models and Treatments. Concussion, 2, CNC50. https://doi.org/10.2217/cnc-2017-0003

[15] Johansson, B. and Bjuhr, H. (2018) Train 4 Good-An Eight-Month Mindfulness Program Live on Internet for Long-Term Mental Fatigue and Emotional Distress after an Acquired Brain Injury. Archives of Psychology, 2, 1-17.

https://doi.org/10.31296/aop.v2i5.61 
[16] Sayegh, A., Sandfor, D. and Carlson, A.J. (2010) Psychological Approaches to Treatment of Postconcussion Syndrome: A Systematic Review. Journal of Neurology, Neurosurgery and Psychiatry, 81, 1128-1134. https://doi.org/10.1136/jnnp.2008.170092

[17] Leddy, J.J., Baker, J.G. and Willer, B. (2016) Active Rehabilitation of Concussion and Post-Concussion Syndrome. Physical Medicine \& Rehabilitation Clinics of North America, 27, 437-454. https://doi.org/10.1016/j.pmr.2015.12.003

[18] Corazon, S.S., Poulsen, D.V., Sidenius, U., Gramkov, M.C., Djernis, D. and Stigsdotter, U.K. (2018) Konceptmanual for Nacadias natur-baserede terapi (in Danish). Department of Geoscience as Natural Ressouce Management, Frederikberg, Denmark.

[19] Kaplan, S. and Kaplan R. (1989) The Experience of Nature: A Psychological Perspective. Cambridge University Press, New York, US.

[20] Stevenson, M.P., Schilhab T. and Bentsen, P. (2018) Attention Restoration Theory: A Systematic Review of the Attention Restoration Potential of Exposure to Natural Environments. Journal of Toxicology \& Environmental Health, 21, 227-268. https://doi.org/10.1080/10937404.2018.1505571

[21] Jordan, M. (2015) Nature and Therapy: Understanding Counseling and Psychotherapy in Outdoor Spaces. Routlegde, East Sussex, UK. https://doi.org/10.4324/9781315752457

[22] Corazon, S.S., Schilhab, T. and Stigsdotter, U.K. (2010) Developing the Therapeutic Potential of Embodied Cognition and Metaphors in Nature-Based Therapy: Lessons from Theory to Practice. Journal of Adventure Education and Outdoor Learning, 11, 161-171. https://doi.org/10.1080/14729679.2011.633389

[23] Johansson, B. and Rönnbäck, L. (2014) Evaluation of the Mental Fatigue Scale and Its Relation to Cognitive and Emotional Functioning after Traumatic Brain Injury or Stroke. International Journal of Physical Medicine \& Rehabilitation, 2, 182.

[24] EuroQol Research Foundation (2019) EQ-5-5L User Guide. https://euroqol.org/docs/EQ-5D-5L-User-Guide.pdf

[25] Burnard, P. (1991) A Method of Analyzing Interview Transcripts in Qualitative Research. Nurse Education Today, 11, 461-466. https://doi.org/10.1016/0260-6917(91)90009-Y

[26] Norrie, J., Heitger, M., Leathem, J., Anderson, T., Jones, R. and Flett, R. (2010) Mild Traumatic Brain Injury and Fatigue: A Prospective Longitudinal Study. Brain Injury, 24, 1528-1538. https://doi.org/10.3109/02699052.2010.531687

[27] Johansson, B., Bjuhr, H. and Rönnbäck, L. (2012) Mindfulness-Based Stress Reduction (MBSR) Improves Long-Term Mental Fatigue after Stroke or Traumatic Brain Injury. Brain Injury, 26, 13-14. https://doi.org/10.3109/02699052.2012.700082

[28] Kaplan, S. (1995) The Restorative Benefits of Nature: Toward an Integrative Framework. Journal of Environmental Psychology, 15, 169-182.

https://doi.org/10.1016/0272-4944(95)90001-2

[29] McGeeny, A. (2007) With Nature in Mind. Jessica Kingsley Publishers, London, UK. 